\title{
Octreotide Prophylaxis Is Not Beneficial for Biochemical Activity and Clinical Severity of Postoperative Pancreatic Fistula after Pancreatic Surgery
}

\author{
R.A. Droeser ${ }^{a, c} \quad$ P. Jeanmonod ${ }^{a} \quad$ J.Schuld ${ }^{a} \quad$ M.R. Moussavian ${ }^{a} \quad$ M.K. Schilling ${ }^{a}$ \\ O. Kollmara, b \\ ${ }^{a}$ Department of General, Visceral, Vascular and Pediatric Surgery, University of Saarland, Homburg \\ ${ }^{b}$ Department of General and Visceral Surgery, University Medical Center Göttingen, Göttingen, Germany \\ 'Department of General and Visceral Surgery, University Hospital of Basel, Basel, Switzerland
}

\section{Key Words}

Pancreatic surgery · Postoperative pancreatic fistula · ISGPF criteria $\cdot$ Octreotide $\cdot$ Lipase activity

\begin{abstract}
Background: Prospective randomized trials indicate that prophylactic octreotide treatment does not decrease the incidence of postoperative pancreatic fistula (POPF). The aim of this study was to analyze if octreotide prophylaxis could decrease the severity grade of POPFs after pancreatic surgery. Method: Seventy-eight of 684 patients undergoing pancreatic resection with POPF were included in the study. Prophylactic octreotide treatment was started immediately after surgery and was performed in 22 patients, whereas 56 patients had no octreotide treatment and served as controls. Lipase activity was measured in the abdominal drainage on postoperative days (POD) 3,5 and 7. Primary endpoints of the study were clinical severity of the POPF and lipase activity in the drainage. Results: There was no significant difference concerning length of postoperative hospital stay. Lipase activity in the abdominal drainage was not influenced by octreotide prophylaxis at POD 5 or 7 compared to POD 3. Multivariate analysis showed that the risk to develop a type $B$ or
\end{abstract}

$C$ fistula in the octreotide group was independent of the kind of operation and the consistency of the pancreas ( $R R=$ $3.4 ; \mathrm{Cl}=1.0-11.7 ; \mathrm{p}=0.050$ and $\mathrm{RR}=6.3 ; \mathrm{Cl}=1.4-29.6 ; \mathrm{p}=$ 0.019). Conclusion: Octreotide prophylaxis after pancreatic surgery has no beneficial effect on clinical severity of POPF.

Copyright $\odot 2012$ S. Karger AG, Basel

\section{Introduction}

Adenocarcinoma of the pancreatic head is the fourth leading cause of cancer related deaths amongst men and women [1]. The standard treatment for complicated chronic pancreatitis and pancreatic epithelial and endocrine tumors is surgery. Generally, resections of the pancreatic head are performed by classical or pylorus-preserving pancreaticoduodenectomy. However, these procedures are associated with high morbidity [2-4]. If the tumor is resectable, the median survival can be prolonged from 9 months up to 18 months; however, the 5-year survival rate after resection remains $11-21 \%$ [2-5]. Although

\section{R.A.D. and P.J. contributed equally to this work.}

\section{KARGER \\ Fax +4161306 1234}

E-Mail karger@karger.com

www.karger.com
(C) 2012 S. Karger AG, Basel

0253-4886/12/0296-0484\$38.00/0

Accessible online at:

www.karger.com/dsu
Raoul A. Droeser, MD

Department of General and Visceral Surgery

University Hospital Basel

CH-4031 Basel (Switzerland)

E-Mail rdroeser@uhbs.ch 
adjuvant chemotherapy with gemcitabine has become the standard treatment for pancreatic cancer, survival could be only prolonged for months [6]. For metastatic disease Folfirinox has recently been shown to be superior to gemcitabine [7]. According to this low 5-year survival rate, the goal of surgery must be to achieve a short hospital stay with low morbidity.

Other types of pancreatic resection, such as pancreatic left or central resection, have a lower morbidity, but postoperative fistula still remains the major cause of postoperative morbidity [8]. Common to all pancreatic surgical manipulations, postoperative pancreatic fistula or postoperative anastomotic leakage (POPF) still remains a major contributor to morbidity after pancreatic surgery and is associated with a number of factors, most of them attributable to pancreatic anatomy like consistency of the pancreas but also to surgical techniques and the operation type $[3,5,8]$. The severity of pancreatic fistula is defined as grade $\mathrm{A}-\mathrm{C}$ based on the need for clinical treatment [9]. As somatostatin inhibits the gastroenteropancreatic exocrine secretion, octreotide, its long-acting analogue, has been studied in multiple randomized controlled trials for the pharmacological prevention of POPF [3,10-14]. However, due to conflicting results, somatostatin and its analogs failed to prevent POPF after pancreatic surgery and are not unequivocally accepted. Therefore, the aim of this study was to analyze the influence of octreotide prophylaxis on biochemical activity and severity of POPF in patients undergoing pancreatic surgery.

\section{Patients and Methods}

Between January 2001 and December 2008, clinical data of 684 consecutive patients undergoing pancreatic resection by 8 different surgeons in our hepatobiliary center were prospectively entered in a single center database on an ISH-Med SAP platform (SAP, St. Leon, Germany). Of these 684 patients, 133 patients developed a POPF (fig. 1). For strong correlation and analysis of the direct influence of prophylactic octreotide treatment on POPF, patients receiving octreotide medication later than the first postoperative day (POD) were excluded from the final analysis ( $\mathrm{n}=$ 55). Therefore, 78 patients could be included in the present study: 22 patients received octreotide prophylaxis directly (within $24 \mathrm{~h}$ ) after the operation, and 56 patients had no treatment with octreotide and served as controls. Patients of the octreotide group received $3 \times 100 \mu \mathrm{g}$ octreotide (Sandostatin ${ }^{\circledR}$, Novartis Pharma GmbH, Nürnberg, Germany) per day subcutaneously. The intention to treat the patients with prophylactic octreotide was based on the decision of the responsible surgeon within $24 \mathrm{~h}$ after the operation.

All patients received antibiotic prophylaxis prior to surgery. In case of a pancreaticoduodenectomy orthotopic reconstruction

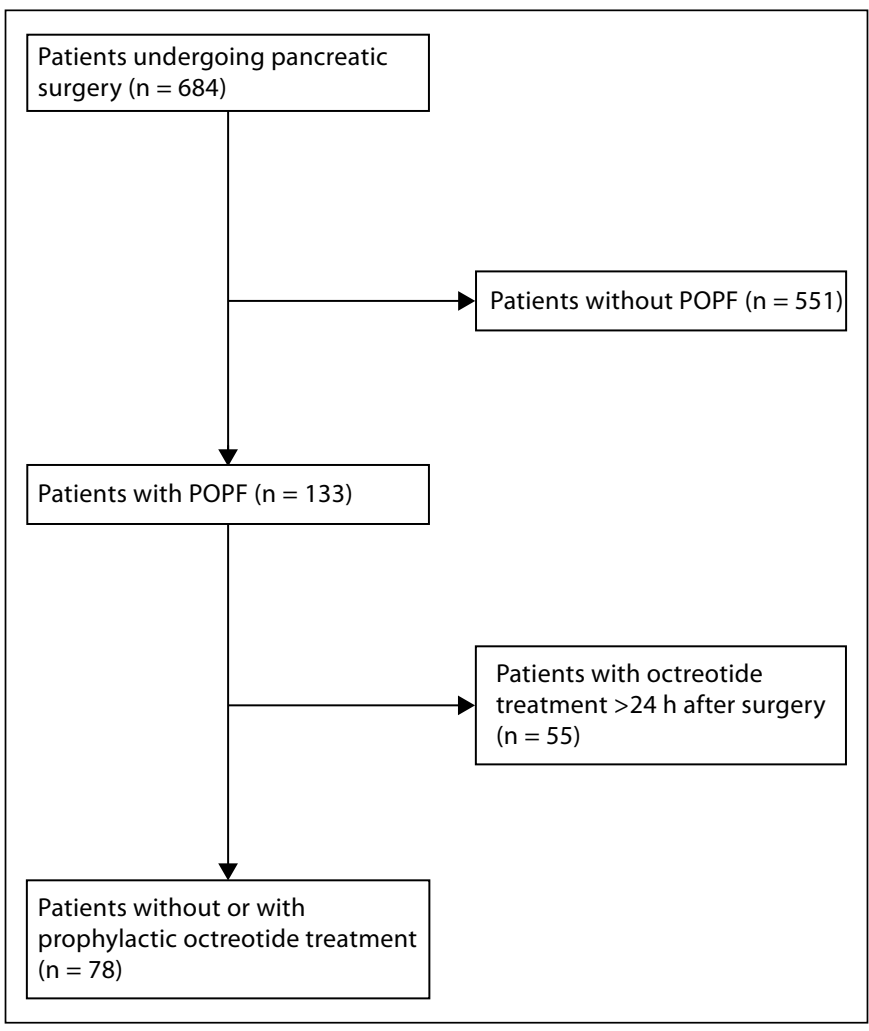

Fig. 1. CONSORT diagram of the study. Octreotide = Prophylactic octreotide treatment within $24 \mathrm{~h}$ after surgery; control = no octreotide treatment.

was performed with end-to-side anastomosis in duct to mucosa technique for the pancreaticojejunostomy, hepaticojejunostomy $10-20 \mathrm{~cm}$ distal to the pancreatojejunostomy and gastrojejunostomy $40 \mathrm{~cm}$ distal to the hepaticojejunostomy on the same jejunal loop [5]. Radical extended lymphadenectomy was routinely performed in patients with malignant disease. Abdominal drainage of the pancreatic anastomosis was performed in all cases. The abdominal drainage was removed after POPF had disappeared.

The clinical severity of POPF was classified according to the ISGPF criteria by Bassi et al. modified by Pratt et al. $[9,15]$. All patients with POPF were treated according to clinical standards for postoperative management (antibiotics, further drainages, reoperations). Both groups (control vs. octreotide) were compared according to age, gender, ASA score (American Society of Anesthesiologists), diagnosis, tumor grading, density of pancreatic parenchyma, type of resection, operation time, intraoperative blood loss, reoperation, antibiotic treatment, postoperative bleeding, fascial dehiscence, wound infection, cardiac and pulmonary complications, urinary tract infection, thrombosis and pulmonary embolism, postoperative delayed gastric emptying, and mortality.

\section{Study Hypothesis and Endpoints}

Data analysis was performed retrospectively. The study hypothesis was that octreotide prophylaxis after pancreatic surgery attenuates the severity of POPF. The grade of POPF and the amount of lipase activity within the drainage at POD 3, 5 and 7 
were defined as primary endpoints. The incidence of the three different fistula grades $(\mathrm{A}-\mathrm{C})$ and the relative risk to develop a severe fistula (grade B and C) were used for analysis of clinical severity. Overall survival, mortality, ICU stay, and postoperative hospital stay were defined as secondary endpoints.

\section{Statistical Analysis}

Data are expressed as absolute numbers or mean \pm SEM unless indicated otherwise. Differences between both groups were calculated as follows: categorical variables were analyzed by $\chi^{2}$ test or Fischer's exact test, whereas continuous variables were analyzed by Student's t test or Mann-Whitney test, as appropriate. Survival data were expressed according to the Kaplan-Meier survival estimates. Overall statistical significance was set at $\mathrm{p}<0.05$ (two-sided p value). Differences of lipase levels between the three time points were analyzed by logarithmic trend analysis. Due to the inhomogeneous distribution of the lipase activity at POD 3 a sensitivity analysis including only patients with a lipase activity of $>5,000 \mathrm{IU} / \mathrm{l}$ was performed. To test the independence of the risk from predictors for a POPF all analyzed parameters of potential predictors of octreotide application with a $p$ value of $<0.15$ in the univariate analysis were entered into a multivariate logistic regression model. Statistical analysis was performed with the use of the software package SPSS 14.0h (SPSS GmbH Software, Munich, Germany).

\section{Results}

Mainly, patients undergoing pylorus-preserving pancreaticoduodenectomy $(n=51)$ or pancreatic left resections were included $(n=20)$. In single cases and depending on the diagnosis, a classic Whipple operation $(\mathrm{n}=3)$, a Frey procedure $(\mathrm{n}=1)$ or a central pancreatic resection $(\mathrm{n}=3)$ was performed. There was a significant difference for the kind of operation with more pancreatic left resections in the control group $(p=0.02)$. Duration of prophylactic octreotide treatment was $11.2 \pm 1.3$ days. Patient's characteristics and operative as well as postoperative data are summarized in tables 1 and 2 . Both groups were comparable according to age, gender, ASA score, inhouse mortality, reoperation rate, fascial dehiscence, wound infections, postoperative bleeding episodes, cardiac and pulmonary complications, urinary tract infection, thrombosis and pulmonary embolism, delayed gastric emptying and postoperative treatment with antibiotics (tables 1,2). Operation time was significantly shorter in the control compared to the octreotide group $(244 \pm 10$ vs. $310 \pm 19 \mathrm{~min} ; \mathrm{p}=0.002)$ and intraoperative blood loss was significantly lower in the control compared to the octreotide group ( $507 \pm 48$ vs. $748 \pm 149 \mathrm{ml}$; $\mathrm{p}=0.049)$. Finally, there was a trend towards a higher frequency of a soft pancreas in the control group (46 vs. $0 \% ; \mathrm{p}=0.053)$.
Table 1. Biographic data of 78 consecutive patients with POPF after pancreatic surgery: 22 patients had prophylactic treatment with octreotide, whereas 56 patients had no treatment with octreotide

\begin{tabular}{llll}
\hline & Control & Octreotide & p value \\
\hline Age, years & $61.2 \pm 2.0$ & $63.4 \pm 2.2$ & 0.535 \\
Gender, M/F & $35 / 21$ & $15 / 7$ & 0.794 \\
ASA score & $2.4 \pm 0.1$ & $2.4 \pm 0.1$ & 0.889 \\
Malignant tumors & $37(66.1 \%)$ & $15(68.2 \%)$ & 1.000 \\
\hline
\end{tabular}

Data are expressed as mean \pm SEM or $n$.

Table 2. Operative details, postoperative complications and follow-up of 78 consecutive patients with POPF after pancreatic surgery: 22 patients had prophylactic treatment with octreotide, whereas 56 patients had no treatment with octreotide

\begin{tabular}{lccc}
\hline & Control & Octreotide & p value \\
\hline Operation time, min & $244 \pm 10$ & $310 \pm 19$ & 0.002 \\
Blood loss, ml & $507 \pm 48$ & $748 \pm 149$ & 0.049 \\
In-hospital mortality & $4(7.1)$ & $4(18.2)$ & 0.212 \\
Postoperative treatment & & & \\
$\quad$ with antibiotics & $45(80.4)$ & $19(86.4)$ & 1.000 \\
Delayed gastric emptying & $22(39.3)$ & $11(50.0)$ & 0.544 \\
Fascial dehiscence & $2(3.6)$ & $3(13.6)$ & 0.133 \\
Wound infection & $6(10.7)$ & $2(9.1)$ & 1.000 \\
Postoperative bleeding & $2(3.6)$ & $5(22.7)$ & 0.084 \\
Cardiac complication & $10(17.9)$ & $4(18.2)$ & 1.000 \\
Pulmonary complication & $10(17.9)$ & $5(22.7)$ & 0.751 \\
Urinary tract infection & $5(8.9)$ & $2(9.1)$ & 1.000 \\
Thrombosis/pulmonary & & & \\
$\quad$ embolism & $4(7.1)$ & $1(4.5)$ & 1.000 \\
Others (abscess, perforation) & $5(8.9)$ & $5(22.7)$ & 0.138 \\
\hline
\end{tabular}

Date are expressed as mean \pm SEM or number (\%).

\section{Effect of Prophylactic Octreotide Treatment on Lipase} Activity - Primary Endpoint

Measurement of lipase activity was performed at POD 3, 5 and 7 within the abdominal drainage (fig. 2a). At POD 3, patients of the octreotide group had a significantly higher lipase activity compared to patients of the control group $(22,356 \pm 6,969$ vs. $8,827 \pm 2,855 \mathrm{IU} / \mathrm{l}$, respectively; $\mathrm{p}=0.035)$. On POD 5 and POD 7, no statistically significant differences could be found comparing lipase activity of the octreotide and control group (21,170 \pm 8,585 vs. $23,988 \pm 9,512 \mathrm{IU} / \mathrm{l}$ and $18,159 \pm 8,382$ vs. 24,530 $\pm 8,393 \mathrm{IU} / \mathrm{l}$, respectively). The overall logarithmic trend 

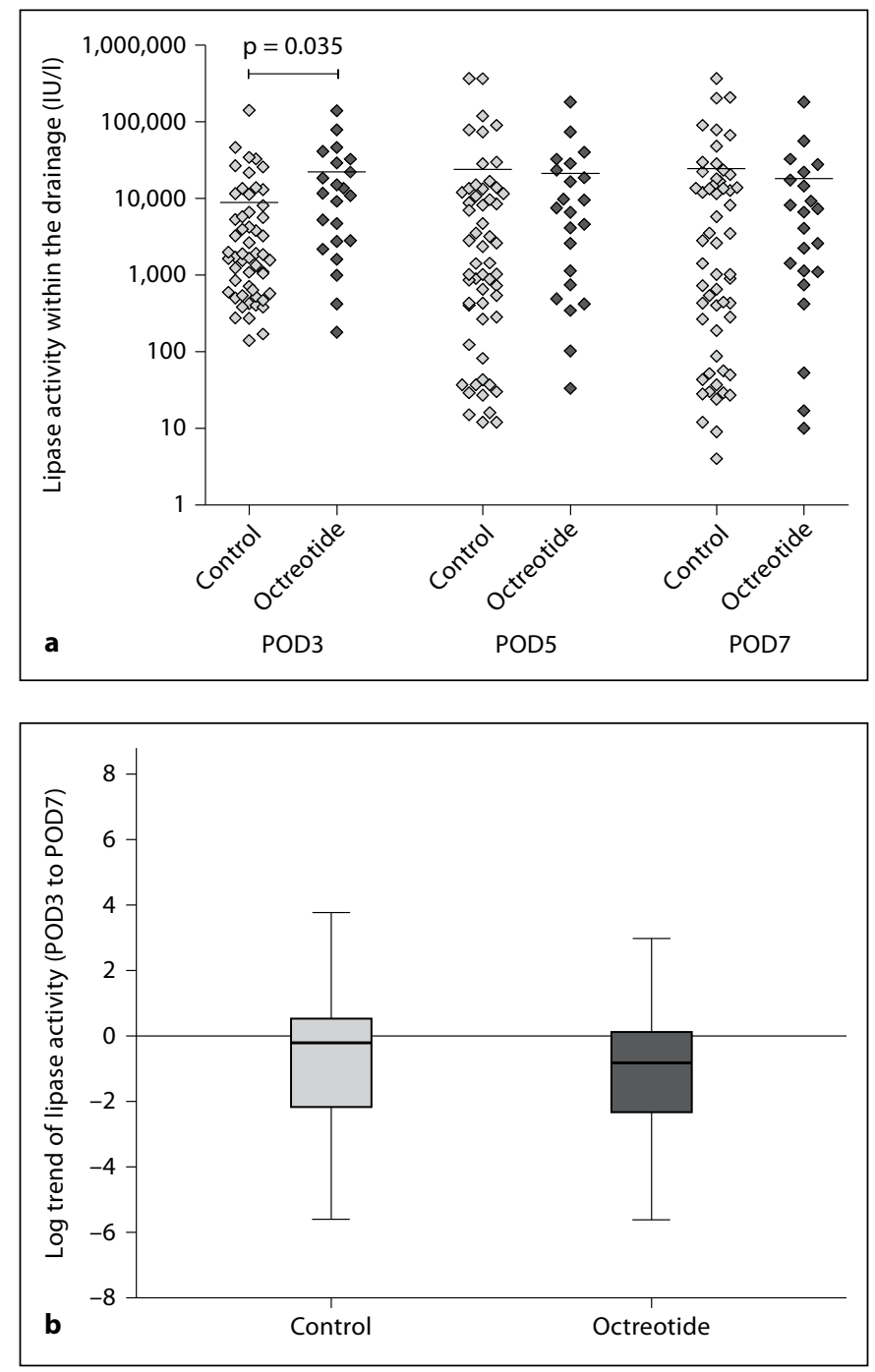

Fig. 2. a Dot plot analysis of absolute lipase values on POD 3, 5 and 7 of all patients in the control group and those in the prophylactic octreotide treatment group. Statistical analyses showed significant higher lipase activity in the octreotide compared to control group at POD $3(\mathrm{p}=0.035)$. On POD 5 and POD 7, no further significant differences could be observed between both groups. The black line represents the mean of the data. b Logarithmic trend analysis of lipase activity within the drainage comparing POD 3 (baseline) versus POD 7. Statistical analysis showed neither a significant increase nor a significant decrease of lipase activity from POD 3 to POD 7 between the octreotide and control group.

analysis, comparing the change of lipase activity between POD 3 and POD 7 in both groups, showed no effect of prophylactic octreotide treatment compared to controls (fig. 2b). No significant increase or significant decrease of lipase activity from POD 3 to POD 7 was noticed within both groups.

Octreotide Prophylaxis and Severity of POPF
Due to the inhomogeneous distribution of the lipase activity at POD 3, a sensitivity analysis was performed including only patients with a lipase activity of $>5,000$ IU/l on POD $3(n=31)$. The cut-off point of a lipase activity of $>5,000 \mathrm{IU} / 1$ was chosen, as a previous study showed that type $\mathrm{C}$ fistulas could be predicted by a high drain lipase activity on POD3. Lipase activity cut-off points other than $>5,000 \mathrm{IU} / \mathrm{l}$, amylase activity or enzyme activity measured on POD5 or POD7 were not predictive for the development of type $C$ fistula in this study [16]. This subgroup analysis included 17 patients of the control and 14 patients of the octreotide group and showed neither a significant increase, nor decrease of lipase activity in the octreotide compared to the control group.

\section{Effect of Octreotide Treatment on Clinical Severity of $P O P F$}

After pancreatic surgery, patients of the control group developed more often POPFs grade A than patients in the octreotide group (table 3a). The relative risk of the patients to develop a clinical severe POPF grade B or C was significantly increased in the octreotide compared to the control group (72.7 vs. $35.7 \%$; $\mathrm{RR}=4.8$; $\mathrm{CI}=1.6-14.2 ; \mathrm{p}=$ 0.005 ; table $3 \mathrm{a}$ ). Furthermore, in the subgroup analysis including only patients with a lipase activity of $>5,000$ IU/l at POD $3(n=31)$, the incidence of POPF grade $C$ was significantly higher in the octreotide compared to the control group ( 35.7 vs. $0 \% ; p=0.012$; table $3 b$ ). In this subgroup, lipase activity was not significantly different between the octreotide and the control group at POD 3 $(\mathrm{p}=0.293)$.

Finally, including all patients (this hypothesis was made a priori), the trend analysis showed that the initial trend of lipase activity (decrease or increase of lipase activity between POD 3 and POD 7) was a predictive factor in developing a POPF grade $\mathrm{C}$ independent from prophylactic octreotide treatment $(\mathrm{RR}=4.2 ; \mathrm{CI}=1.1-16.2 ; \mathrm{p}=$ $0.035)$. When lipase activity increased $(\mathrm{n}=26) 7$ patients developed a POPF grade C (26.9\%) whereas only 4 (8.0\%) of 50 patients developed a POPF grade $\mathrm{C}$ when lipase activity decreased. Definitive diagnosis (malign vs. benign), the type of lymphadenectomy and the size of the pancreatic duct had no predictive impact on the grade of POPF in this patient cohort.

\section{Multivariate Analysis}

In a multivariate analysis adjusted for the kind of operation and the consistency of the pancreas, the risk to develop a type B fistula or a type C fistula was significantly increased in the octreotide group compared to the 
Table 3a. Clinical severity of POPF in 78 patients undergoing pancreatic surgery: 22 patients had prophylactic treatment with octreotide, whereas 56 patients had no treatment with octreotide

\begin{tabular}{llc}
\hline POPF & Control (\%) & Octreotide (\%) \\
\hline Total & $56(100)$ & $22(100)$ \\
Grade A & $36(64.3)$ & $6(27.3)$ \\
Grade B & $15(26.8)$ & $10(45.4)$ \\
Grade C & $5(8.9)$ & $6(27.3)$ \\
\hline
\end{tabular}

Comparing both groups according to the incidence of POPF grade $\mathrm{A}, \mathrm{B}$ and $\mathrm{C}$, patients of the octreotide group developed significantly more grade $B$ and $C$ fistula $(\mathrm{p}=0.001)$.

Table 3b. Clinical severity of POPF with a lipase activity of $>5,000$ IU/l at POD 3 after pancreatic surgery: 14 patients had prophylactic treatment with octreotide, whereas 17 patients had no treatment with octreotide

\begin{tabular}{lcc}
\hline POPF & Control (\%) & Octreotide (\%) \\
\hline Total & $17(100)$ & $14(100)$ \\
Grade A & $15(88.2)$ & $2(14.3)$ \\
Grade B & $2(11.8)$ & $7(50.0)$ \\
Grade C & $0(0.0)$ & $5(35.7)$ \\
\hline
\end{tabular}

Comparing both groups according to the incidence of POPF grade $\mathrm{A}, \mathrm{B}$ and $\mathrm{C}$ patients of the octreotide group developed significantly more grade $C$ fistula $(\mathrm{p}=0.012)$.

control group $(\mathrm{RR}=3.4 ; \mathrm{CI}=1.0-11.7 ; \mathrm{p}=0.050$ and $\mathrm{RR}=$ $6.3 ; \mathrm{CI}=1.4-29.6 ; \mathrm{p}=0.019$, respectively).

\section{Hospital Stay and Overall-Survival - Secondary Endpoints}

Comparing both groups with POPF after pancreatic surgery there was no statistical significance regarding the overall survival (control $45.6 \pm 4.3$ vs. octreotide $35.2 \pm$ 6.2 months; $p=0.103)$. Excluding the patients with inhospital mortality $(n=8)$, overall survival was not significantly different between the control and octreotide group ( $50.2 \pm 4.2$ vs. $42.8 \pm 6.3$ months, respectively; $\mathrm{p}=$ 0.197; fig. 3a). Furthermore, excluding patients with inhospital mortality, no significant difference in survival could be found for patients with malignant tumors (39.4 \pm 4.3 vs. $29.0 \pm 5.7$ months; $\mathrm{p}=0.121$; fig. $3 \mathrm{~b}$ ) and patients with benign tumors between the two groups (fig. 3c). Overall hospital stay, as well as stay on the intensive care unit were comparable between the control and the oc- treotide group (4.5 vs. 7.5 and 19.5 vs. 23.2 days; respectively). Patients with POPF grade $\mathrm{C}(\mathrm{n}=11)$ had a significantly higher $(\mathrm{p}<0.001)$ in-hospital mortality compared to patients with POPF grade A or B.

\section{Discussion}

The influence of octreotide on the pharmacological prevention of POPF has been studied in multiple randomized controlled trials [3, 10-14]. While some European studies described a significant reduction of the incidence of POPF after pancreas resection using prophylactic octreotide treatment, several international studies failed to demonstrate this beneficial effect [11-14, 1723]. In a recently published meta-analysis, the overall incidence of POPF was lower in the group receiving prophylactic octreotide. However, in an analysis of trials that clearly distinguished clinically significant fistulas no influence of prophylactic octreotide treatment on the incidence of POPF could be found [24]. Furthermore, another review article also found no beneficial effect of prophylactic octreotide treatment after pancreatic surgery [25]. Taken together, to our knowledge there is no consensus in the literature whether somatostatin and its analogues reduce the incidence and/or severity of POPF after pancreatic surgery. The optimal treatment in case of a POPF depends on the clinical severity as well as on the clinical manifestation of the POPF. Complicated POPFs of type $\mathrm{C}$ are usually associated with worse clinical conditions (infection, sepsis) and require interventional therapy by puncture or even reoperation. Monitoring on the ICU is mandatory, as POPF type $\mathrm{C}$ has a significant increased risk for fistula related death $[9,15]$.

However, as the influence of prophylactic octreotide treatment after pancreatic surgery on the severity of POPF has not been described in the literature, the current study included patients with POPF after pancreatic surgery without octreotide prophylaxis and with prophylactic octreotide treatment. The inhomogeneous patient's cohort with octreotide treatment at a later time point was excluded. The current analysis demonstrated that prophylactic octreotide treatment after pancreatic surgery had no beneficial effect on the clinical severity of POPF according to the ISGPF criteria. The individual risk to develop a severe POPF grade $\mathrm{C}$ was directly aggravated by octreotide treatment. Furthermore, it could be demonstrated that the initial lipase activity was a prognostic factor to develop a severe POPF with a significantly high- 


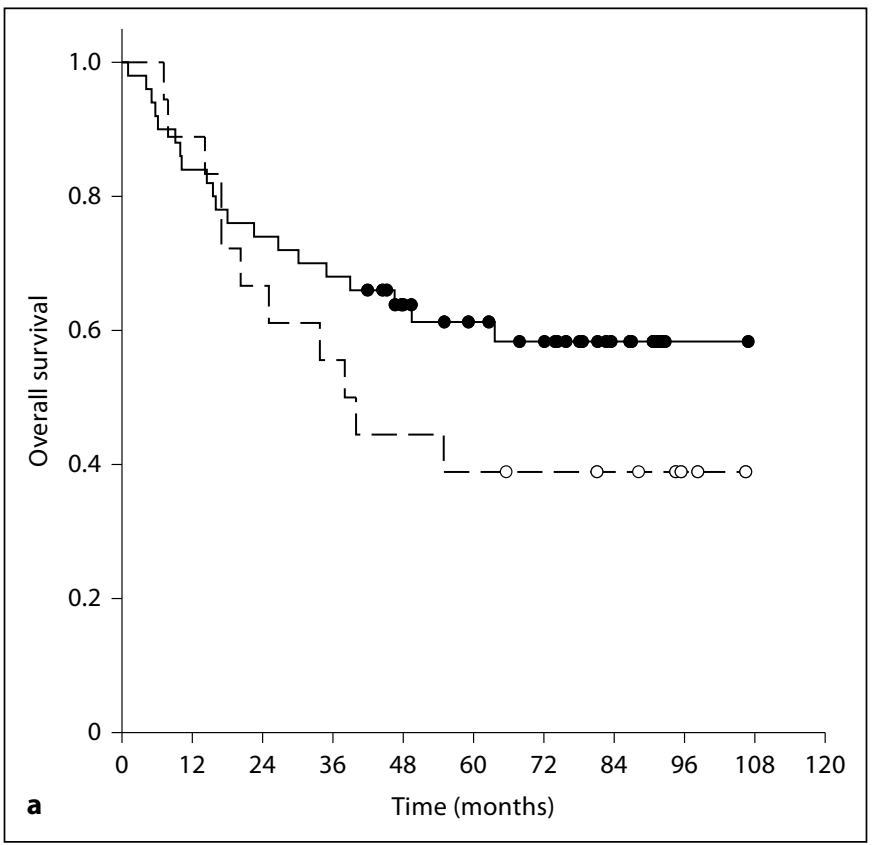

Fig. 3. Kaplan-Meier survival curves of patients with POPF after pancreatic surgery. a All 78 patients excluding patients with inhospital mortality. Excluding patients with in-hospital mortality, b presents only patients with malignant tumors, whereas c presents only patients with benign tumors. Statistical analysis was performed between the control group (control, solid black line) and the prophylactic octreotide treatment group (dashed black line) without statistical differences between both groups.

er lipase activity at POD 3 after prophylactic octreotide treatment.

The goal of pancreatic surgery should be to achieve a short hospital stay with low morbidity, especially in the case of pancreatic cancer, which has a 5-year survival of only $11-21 \%$ [2]. As POPF is a common and major complication after pancreatic surgery, with a frequency of up to $40 \%$, this complication plays a major role regarding postoperative morbidity. The optimal medical and surgi-

Octreotide Prophylaxis and Severity of POPF
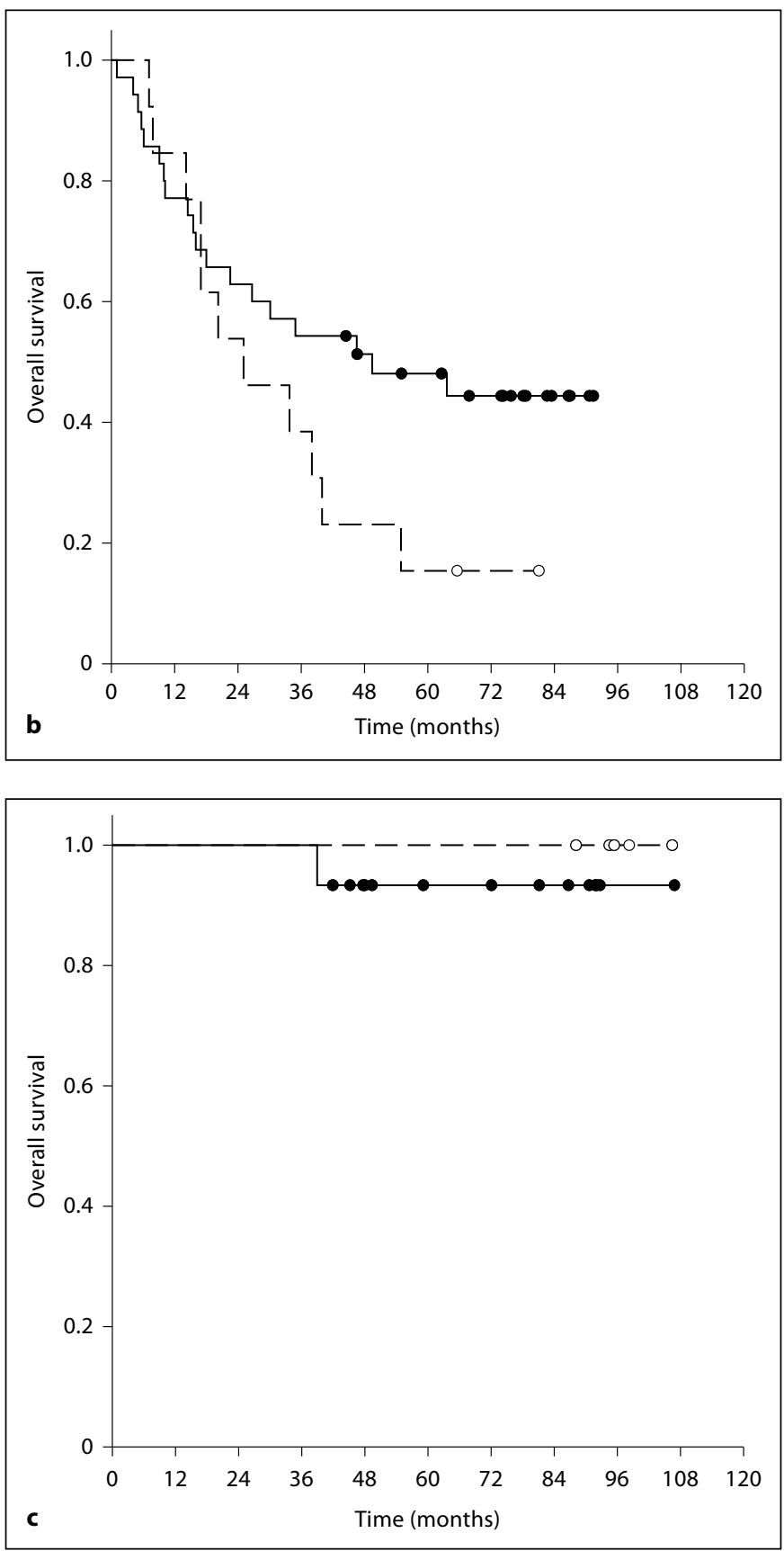

cal management of POPF should help reduce its incidence and severity. In this context, the current study showed that prophylactic octreotide treatment did not influence biochemical lipase activity. The reason for the negative influence of prophylactic octreotide treatment on the clinical severity of POPF in the current analysis is therefore difficult to interpret. The effect of octreotide on the visceral organs is complex. The physiological effect of octreotide on pancreatic perfusion and exocrine secre- 
tion is still controversial [26]. On one hand, octreotide decreases the perfusion of the pancreas and/or the small intestine in animal models, which may explain the missing benefit on the incidence of POPF $[3,27,28]$. Furthermore, an increased bacterial translocation from the gut was found in octreotide-treated rats [29]. On the other hand, exocrine pancreatic secretion seems to be reduced by octreotide [26]. However, as octreotide prophylaxis is more detrimental than beneficial in terms of clinical severity of POPF our observations demonstrate that the mechanism underlying the missing benefit on biochemical activity is still not fully understood.

The limitations of the present retrospective study are the low sample size and a possible selection bias by the responsible surgeon. The intention for prophylactic octreotide treatment was based on the subjective decision of the surgeon and not randomly assigned. Using multivariate analysis including predictors for POPF such as the kind of operation and the consistency of the pancreas, the risk to develop a type $\mathrm{B}$ or $\mathrm{C}$ fistula in the octreotide group was still significantly increased. Otherwise, at the time of surgeons' decision the development of a POPF was unknown. Furthermore, there was a significant dif- ference for the kind of operation with more pancreatic left resections in the control group $(\mathrm{p}=0.02)$. In the literature, the incidence for POPF after pancreatic surgery is not associated with the type of operation [8]. Even though the power of the study is weak these results do not support the prophylactic use of octreotide after panceratic surgery.

In conclusion, our results demonstrate that prophylactic octreotide treatment after pancreatic surgery has no beneficial effect on POPF. With regard to the higher mortality of complicated POPFs and the aggravation of the clinical severity of the POPF by use of octreotide prophylaxis in our study, prophylactic octreotide treatment after pancreatic surgery should be avoided. However, the use of octreotide in established POPFs after pancreatic surgery still remains to be determined by randomized controlled trials.

\section{Disclosure Statement}

The authors declare that they have no conflict of interest.

\section{References}

1 Siegel R, Ward E, Brawley O, Jemal A: Cancer statistics, 2011: the impact of eliminating socioeconomic and racial disparities on premature cancer deaths. CA Cancer J Clin 2011;61:212-236.

2 Diener MK, Fitzmaurice C, Schwarzer G, Seiler CM, Antes G, Knaebel HP, Buchler MW: Pylorus-preserving pancreaticoduodenectomy (pp Whipple) versus pancreaticoduodenectomy (classic Whipple) for surgical treatment of periampullary and pancreatic carcinoma. Cochrane Database Syst Rev 2011;5:CD006053.

- 3 Kollmar O, Moussavian MR, Richter S, de Roi P, Maurer CA, Schilling MK: Prophylactic octreotide and delayed gastric emptying after pancreaticoduodenectomy: results of a prospective randomized double-blinded placebo-controlled trial. Eur J Surg Oncol 2008;34:868-875.

$\checkmark 4$ Halloran CM, Ghaneh P, Bosonnet L, Hartley MN, Sutton R, Neoptolemos JP: Complications of pancreatic cancer resection. Dig Surg 2002;19:138-146.

5 Kollmar O, Sperling J, Moussavian MR, Kubulus D, Richter S, Schilling MK: Delayed gastric emptying after pancreaticoduodenectomy: influence of the orthotopic technique of reconstruction and intestinal motilin receptor expression. J Gastrointest Surg
2011;15:1158-1167.

6 Oettle H, Neuhaus P: Adjuvant therapy in pancreatic cancer: a critical appraisal. Drugs 2007;67:2293-2310.

7 Conroy T, Desseigne F, Ychou M, Bouche O, Guimbaud R, Becouarn Y, Adenis A, Raoul JL, Gourgou-Bourgade S, de la FC, Bennouna J, Bachet JB, Khemissa-Akouz F, PereVerge D, Delbaldo C, Assenat E, Chauffert B, Michel P, Montoto-Grillot C, Ducreux M: FOLFIRINOX versus gemcitabine for metastatic pancreatic cancer. N Engl J Med 2011; 364:1817-1825.

8 Diener MK, Seiler CM, Rossion I, Kleeff J, Glanemann M, Butturini G, Tomazic A, Bruns CJ, Busch OR, Farkas S, Belyaev O, Neoptolemos JP, Halloran C, Keck T, Niedergethmann $\mathrm{M}$, Gellert $\mathrm{K}$, Witzigmann $\mathrm{H}$, Kollmar O, Langer P, Steger U, Neudecker J, Berrevoet F, Ganzera S, Heiss MM, Luntz SP, Bruckner T, Kieser M, Büchler MW: Efficacy of stapler versus hand-sewn closure after distal pancreatectomy (DISPACT): a randomised, controlled multicentre trial. Lancet 2011;377:1514-1522.

-9 Bassi C, Dervenis C, Butturini G, Fingerhut A, Yeo C, Izbicki J, Neoptolemos J, Sarr M, Traverso W, Buchler M: Postoperative pancreatic fistula: an international study group (ISGPF) definition. Surgery 2005;138:8-13. $\checkmark 10$ Büchler M, Friess H, Klempa I, Hermanek P, Sulkowski U, Becker H, Schafmayer A, Baca I, Lorenz D, Meister R: Role of octreotide in the prevention of postoperative complications following pancreatic resection. Am J Surg 1992;163:125-130.

11 Berberat PO, Friess H, Uhl W, Büchler MW: The role of octreotide in the prevention of complications following pancreatic resection. Digestion 1999;60(suppl 2):15-22.

12 Hesse UJ, De Decker C, Houtmeyers P, Demetter P, Ceelen W, Pattyn P, Troisi R, de Hemptinne B: Prospectively randomized trial using perioperative low dose octreotide to prevent organ related and general complications following pancreatic surgery and pancreatico-jejunostomy. Acta Chir Belg 2005;105:383-387.

13 Li-Ling J, Irving M: Somatostatin and octreotide in the prevention of postoperative pancreatic complications and the treatment of enterocutaneous pancreatic fistulas: a systematic review of randomized controlled trials. Br J Surg 2001;88:190-199.

- 14 Suc B, Msika S, Piccinini M, Fourtanier G Hay JM, Flamant Y, Fingerhut A, Fagniez PL, Chipponi J: Octreotide in the prevention of intra-abdominal complications following elective pancreatic resection: a prospective, multicenter randomized controlled trial Arch Surg 2004;139:288-294. 
15 Pratt WB, Maithel SK, Vanounou T, Huang ZS, Callery MP, Vollmer CM Jr: Clinical and economic validation of the International Study Group of Pancreatic Fistula (ISGPF) classification scheme. Ann Surg 2007;245: 443-451.

16 Frymerman AS, Schuld J, Ziehen P, Kollmar O, Justinger C, Merai M, Richter S, Schilling MK, Moussavian MR: Impact of postoperative pancreatic fistula on surgical outcome the need for a classification-driven risk management. J Gastrointest Surg 2010;14:711-718

17 Bassi C, Falconi M, Lombardi D, Briani G, Vesentini S, Camboni MG, Pederzoli P: Prophylaxis of complications after pancreatic surgery: results of a multicenter trial in Italy. Italian Study Group. Digestion 1994;55(suppl 1):41-47.

18 Bassi C, Falconi M, Pederzoli P: Role of somatostatin and somatostatin analogues in the treatment of gastrointestinal diseases: prevention of complications after pancreatic surgery. Gut 1994;35:S20-S22.

-19 Friess H, Klempa I, Hermanek P, Sulkowski U, Uhl W, Beger HG, Büchler MW: Prophylaxis of complications after pancreatic surgery: results of a multicenter trial in Germany. Digestion 1994;55(suppl 1):35-40.
20 Friess H, Büchler MW: Efficacy of somatostatin and its analogues in pancreatic surgery and pancreatic disorders. Digestion 1996;57(suppl 1):97-102.

21 Gouillat C: Somatostatin for the prevention of complications following pancreatoduodenectomy. Digestion 1999;60(suppl 3):59-63.

22 Montorsi M, Zago M, Mosca F, Capussotti L, Zotti E, Ribotta G, Fegiz G, Fissi S, Roviaro G, Peracchia A: Efficacy of octreotide in the prevention of pancreatic fistula after elective pancreatic resections: a prospective, controlled, randomized clinical trial. Surgery 1995;117:26-31.

23 Graham JA, Johnson LB, Haddad N, Al-Kawas F, Carroll J, Jha R, Wong J, Maglaris D, Mertens S, Fishbein T: A prospective study of prophylactic long-acting octreotide in highrisk patients undergoing pancreaticoduodenectomy. Am J Surg 2011;201:481-485.
24 Koti RS, Gurusamy KS, Fusai G, Davidson BR: Meta-analysis of randomized controlled trials on the effectiveness of somatostatin analogues for pancreatic surgery: a Cochrane review. HPB (Oxf) 2010;12:155-165.

25 Lai EC, Lau SH, Lau WY: Measures to prevent pancreatic fistula after pancreatoduodenectomy: a comprehensive review. Arch Surg 2009; 144:1074-1080.

26 Harris AG: Somatostatin and somatostatin analogues: pharmacokinetics and pharmacodynamic effects. Gut 1994;35:S1-S4.

27 Carlsson PO, Jansson L: The long-acting somatostatin analogue octreotide decreases pancreatic islet blood flow in rats. Pancreas 1994;9:361-364.

28 Conway DR, Djuricin G, Prinz RA: The effect of somatostatin analogue (SMS 201-995) on pancreatic blood flow. Surgery $1988 ; 104$ : 1024-1030.

29 Turkcapar AG, Ersoz S, Gur U, Yerdel MA, Karaaslan A, Erden E, Kuterdem E: The effect of octreotid on bacterial translocation from the gut. An experimental study. Int Surg 1995;80:264-266. 